\title{
Synthesis and Characterization of Nickel-Based Superalloy Materials for Manufacturing Aircraft Turbine Blades
}

\author{
Rezza Ruzuqi ${ }^{1, a)}$, Djony Izak Rudyardjo², Andi Hamim Zaidan ${ }^{3}$ \\ ${ }^{1,2,3}$ School of Physics, Department of Physics, Faculty of Science and Technology, Universitas Airlangga, \\ Surabaya, Jawa Timur, Indonesia \\ ${ }^{a)}$ Email: rezza_ruzuqi@yahoo.com
}

Article History

Received : October 2021, Revised : November 2021, Accepted : November 2021, Online : December 2021

\begin{abstract}
The research has been conducted to manufacture nickel-based Superalloy materials. The purpose of this research was to find out the effects of variation of nickel composition on physical and mechanical properties of the Superalloy materials and find out the appropriate composition of Superalloy materials as materials for turbine blades. This research used nickel, cobalt, chromium, molybdenum, aluminium, and titanium commercial. The results showed that with more addition of nickel composition, the density and hardness values increased. This research showed that nickel-based Superalloy material $59 \mathrm{wt} \%$ was better applied as materials for turbine blades. It is also supported by the results of the test microstructure, where the structure of the sample morphology is more delicate and denser and contains smaller pores. Based on the XRD test results are also shown in the sample has been formed Superalloys phase. Keywords: Nickel Superalloys, Turbine blades, the density of value, hardness, microstructure, and XRD
\end{abstract}

\section{INTRODUCTION}

Along with the advancement of the aviation industry, companies that have significantly contributed to the industry have created various kinds of aircraft components that have superior physical, mechanical and chemical properties to meet market demands [1]. By having superior physical properties, mechanical properties, and chemical properties, it is expected to increase the aircraft's operational life [2,3].

So far, Indonesia is still importing components for aircraft engine maintenance. Importing these components takes a long time, while the replacement of these components must be carried out immediately. Thus, the process is less effective to hinder the development of the aviation industry in Indonesia.

In Indonesia, there is an aviation industry called PT Dirgantara Indonesia, which can compete with the global aviation industry. So far, PT DI has been a sub-contractor for the world's major aircraft industries such as Boeing, Airbus, General Dynamic, and Fokker. In addition, PT DI also produces various aircraft, helicopters, weapons, provides training and maintenance services for aircraft engines.

PT Dirgantara Indonesia is also expected to produce components with superior physical, mechanical and chemical properties, which can later be applied directly without importing aircraft engine components, especially if we have to wait a long time to get them. In this case, especially in the manufacture of components of aircraft turbine blades.

The production of aircraft turbine blades generally uses nickel-based superalloys [4]. The advantages of mining products, especially nickel in Indonesia, are expected to produce their turbine blades with production costs which will undoubtedly be more economical. Therefore, it is necessary to manufacture turbine blades from nickelbased superalloys with superior physical, mechanical and chemical properties. Thus, it is expected to be able to compete with the world's manufacturers of turbine blades.

So far, the physical properties of imported turbine blades include density, melting point, thermal conductivity and coefficient of thermal expansion $8.25 \mathrm{gram} / \mathrm{cm}^{3}, 2430 \mathrm{~F}, 80 \mathrm{~W} / \mathrm{m} \mathrm{K}$, and $7.5 \mathrm{~m} / \mathrm{m} \mathrm{K}$, respectively [5]. Meanwhile, the mechanical properties of imported turbine blades include ultimate tensile strength, yield 
strength at $0.2 \%$ offset, elongation in 2 inches $(50.8 \mathrm{~mm})$, and hardness are $1117 \mathrm{MPa}, 852 \mathrm{MPa}, 21 \%$, and 426.58 . HVN, respectively [6].

From the existing physical and mechanical properties, there is still damage caused. The damage includes cracks in the turbine blades that, if left unchecked, will worsen, so that it can endanger flight safety. Based on these reasons, a nickel-based superalloy material will be re-synthesized by varying the nickel composition to obtain better physical and mechanical properties of turbine blades [7,8].

The material for making turbine blades must be resistant to high temperatures, have good density and hardness because the turbine blades will be placed on the back of the aircraft engine [7]. Superalloy materials are suitable for application as turbine blades, especially nickel-based Superalloy materials [8,9]. It is suitable because nickel has a high melting point, so it is heat resistant and added reinforcement by alloys of other elements in smaller amounts $[10,11]$.

The research will be conducted on the synthesis and characterization of Nickel-Based Superalloy Materials as Materials for Aircraft Turbine Blades from the above description. In order to determine the physical and mechanical properties of the best nickel-based superalloy, characterization will be carried out, including density, hardness, XRD, and microstructure.

\section{METHODOLOGY}

The research was carried out for five months at the Material Physics Laboratory of BATAN Bandung to synthesize and test the mechanical properties of nickel alloys. The microstructure test phase at the Materials Characterization Laboratory of the Ten November Institute of Technology.

The method used to manufacture this Superalloy material sample is pelletizing with a diameter and compressive strength of $1.14 \mathrm{~cm}$ and $150 \mathrm{Kg} / \mathrm{cm}^{2}$, respectively, in the manufacture of samples carried out variations in the addition of nickel using a sintering temperature of $1000^{\circ} \mathrm{C}$ for 1 hour. These characterizations include: Density test was carried out to determine the value of atomic density that has been formed, a compression test was carried out to determine the mechanical strength, XRD test was carried out to determine whether the gamma phase had formed in this Superalloy material, and microscopic structure observations with an optical microscope were carried out to observe the structure. The surface of the material will support the results of the density test and compression test.

\section{RESULT AND DISCUSSION}

\section{Synthesis Results}

This synthesis process uses the composition of Ni-Co-Cr-Mo-Al-Ti with nickel variations of (wt.-\%) 53, 56, and 59, then milled for 60 minutes. Furthermore, the material is made into pellets using a compacting machine with a diameter and compressive strength of $1.14 \mathrm{~cm}$ and $150 \mathrm{~kg} / \mathrm{cm}^{2}$, respectively. After pelletizing process is complete, all materials are sintered at $1000^{\circ} \mathrm{C}$ in an argon atmosphere. The results of the synthesis with variations in nickel concentration are shown in Figure 1.

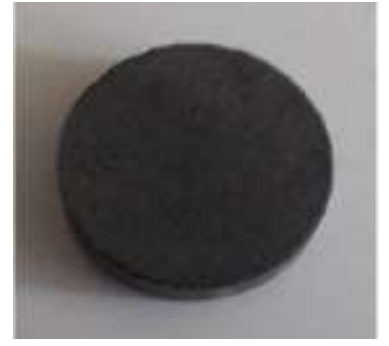

(a) 53 wt.-\%

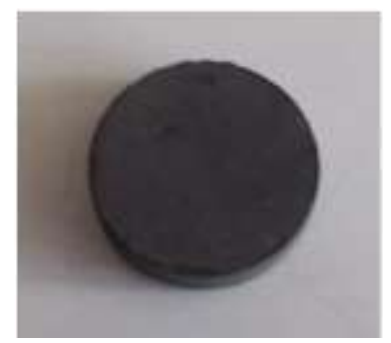

(b) 56 wt.- \%

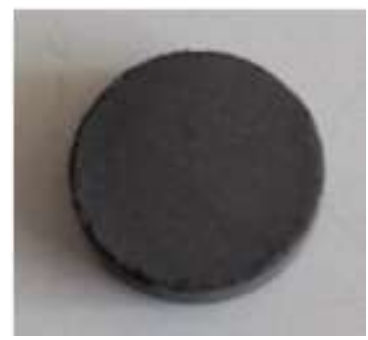

(c) 59 wt. \%

FIGURE 1. Synthesized samples

\section{Test Characterization Results}

\section{Density}

Based on the density test carried out on the sample, the results are shown in Table 1.

TABLE 1. Density test results on samples before sintering 


\begin{tabular}{rrr}
\hline No & Nickel Concentration (wt.- $\%)$ & $\boldsymbol{\rho}\left(\mathbf{g} / \mathbf{c m}^{\mathbf{3}}\right)$ \\
\hline 1. & 53 & 4,581 \\
2. & 56 & 4,650 \\
3. & 59 & 4,712 \\
\hline
\end{tabular}

Table 2 shows the results of the density test on the sample after sintering.

TABLE 2. Density test results on samples after sintering

\begin{tabular}{|c|c|c|}
\hline No & Nickel Concentration (wt.-\%) & $\rho\left(\mathrm{g} / \mathrm{cm}^{3}\right)$ \\
\hline 1. & 53 & 4,636 \\
\hline 2. & 56 & 4,696 \\
\hline 3. & 59 & 4,826 \\
\hline
\end{tabular}

This process aims for samples that have gone through the sintering process to have a density value of $8-8.2$ $\mathrm{g} / \mathrm{cm}^{3}$. Meanwhile, the results show that the values obtained ranged from 4.6 to $4.8 \mathrm{~g} / \mathrm{cm}^{3}$. From Table 1 and Table 2 , it can be seen that there are differences between the samples before sintering and after sintering. These differences can happen because the samples before sintering have not formed bonds. The heat causes the particles to stick together, and the effectiveness of the surface tension reaction increases. In other words, the sintering process causes the particles to stick together so that the density increases. During this process, grain boundaries are formed, which is the recrystallization stage [12].

Overall, the density value obtained has reached $>50 \%$ of the target. These results show that the higher the nickel content in making nickel-based superalloy materials is, the higher the density value of the material. That way, the quality that will be obtained on nickel-based Superalloy materials will also increase.

\section{Hardness Test}

The Vickers hardness test method consists of indenting the test material with a diamond indenter, in the shape of a pyramid with a square base and an angle of 136 degrees between opposite faces subjected to a test force of between $1 \mathrm{gf}$ and $100 \mathrm{kgf}$. A whole load is usually applied for 10 to 15 seconds. In this case, the hardness value to be achieved follows the hardness value in Superalloy Rene. Based on the tests that have been carried out, the results are shown in Table 3.

TABLE 3. Hardness test results on samples

\begin{tabular}{ccc}
\hline No & Nickel Concentration (wt.-\%) & VHN \\
\hline 1. & 53 & 542,7 \\
2. & 56 & 593,4 \\
3. & 59 & 728,0 \\
\hline
\end{tabular}

From the table of hardness test results, a graph of variations in Nickel concentration and the hardness value of nickel-based superalloy materials can be made, as shown in Figure 2.

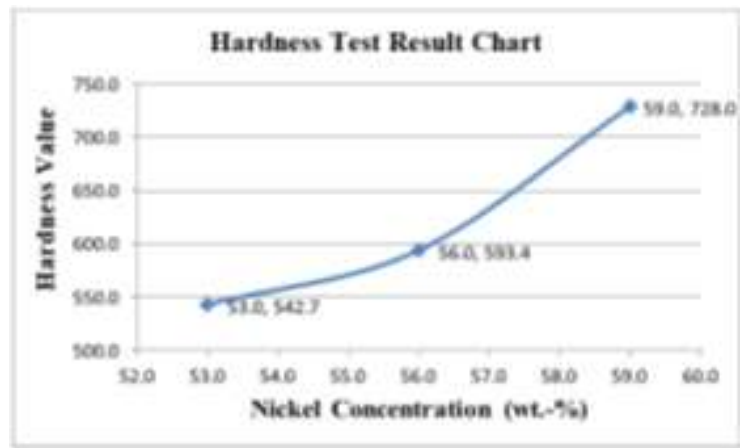

FIGURE 2. The hardness value of Superalloy Materials with variations in nickel concentration 
From the table, it can be seen that the best results are samples containing a lot of nickel $59 \mathrm{wt} .-\%$. The hardness value achieved is $728.0 \mathrm{VHN}$. These results can be produced due to the significant nickel content in the material [10].

Figure 2 shows the results of the hardness tests. It shows that the value increases with the addition of nickel in the superalloy material. These results indicate a correlation between the addition of nickel to the hardness value of the superalloy material. The greater the nickel content in the nickel-based superalloy material, the higher the hardness level of the material.

These results also prove that the greater the nickel content in this nickel-based superalloy material, the better the quality produced. The content that must be given to this nickel-based Superalloy material is 59 wt.- $\%$. The addition of nickel to this nickel-based Superalloy material must also pay attention to the properties produced by the Superalloy material.

\section{XRD Test}

XRD test is used to determine whether $\gamma$ dan $\gamma^{\prime}$ phases have been formed in this nickel-based superalloy material. Several conditions must be met for a sample to be XRD tested $[13,14]$. One of them is that the sample is not in liquid form. Using the XRD test, it is hoped that later we will know the phase formed in the nickel-based superalloy material that has been synthesized. The XRD test results will be obtained from the tests carried out, as shown in Figure 3.

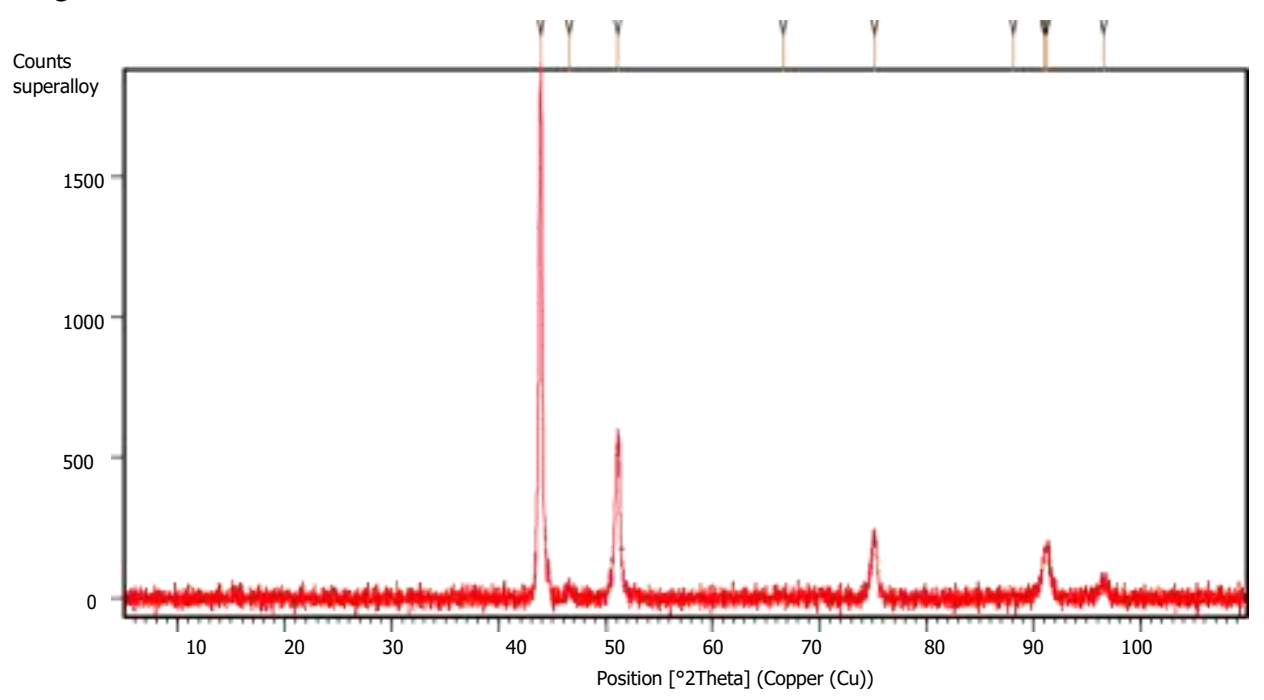

FIGURE 3. XRD test results on synthetic nickel-based superalloy materials

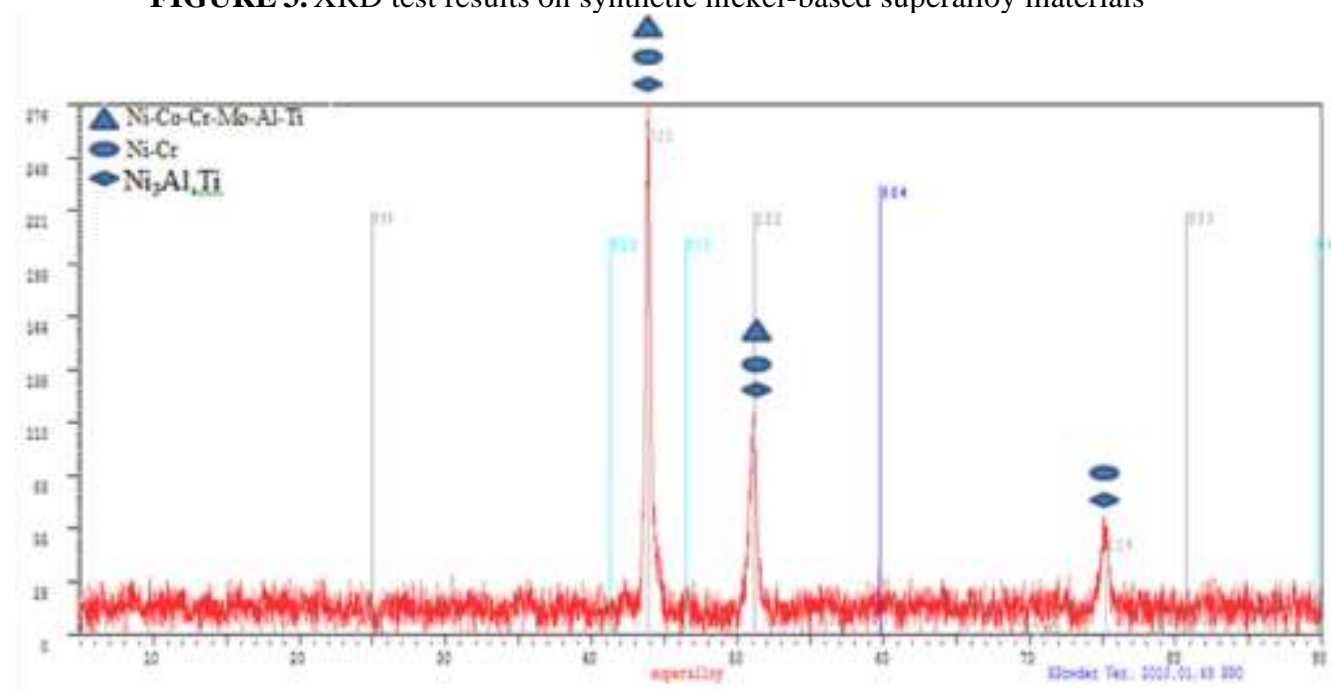

FIGURE 4. XRD test results on synthetic nickel-based superalloy materials

Figure 3 shows the XRD test results of the synthetic nickel-based Superalloy material. In Figure 3, five peaks are formed at 2 Theta angles $40^{\circ}-100^{\circ}$. The 2 Theta shows the characteristics of the nickel-based 
Superalloy material. Also, it shows the formation of a gamma microstructure from the nickel-based Superalloy material, which makes it have a high hardness value and can be applied at high room temperatures $\left(>650^{\circ} \mathrm{C}\right)$.

Figure 4 shows the XRD results of the synthesized Superalloy material. A gamma matrix $(\gamma)$ phase has been formed in the planes (122), (222), and (224). This phase can be formed because there are fused nickel and chromium particles. Therefore, the nickel-based superalloy material that is the result of this synthesis has a high hardness value.

In Figure 4. there is also gamma prime $\left(\gamma^{\prime}\right)$ phases in the planes (122), (222), and (224) which make this nickel-based superalloy material have resistance at high room temperatures, it is beneficial in its application.

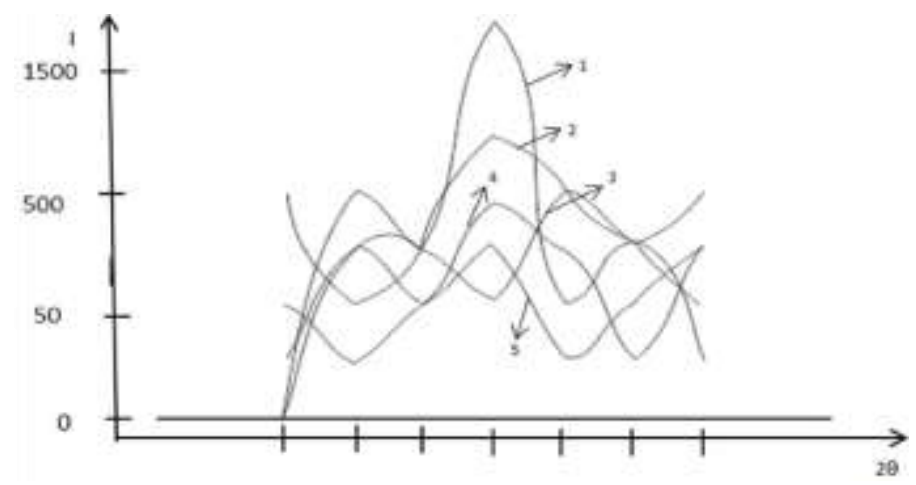

FIGURE 5. The intersection of the peaks of the XRD test results on the nickel-based superalloy synthesized

After getting five peaks for the fields (122), (222), (224), (144), and (241), which are in 2 Theta $40^{\circ}-100^{\circ}$ from Figure 3, then we take the five peaks and then separate them to analyze the row profiles as shown in Figure 5. Finally, we will find that all reflections have complex profiles showing the superposition of several peaks resulting in the complex geometry of each reflection.

\section{Microstructure Test}

The function of this test is to prove whether the resulting surface structure will affect the mechanical properties of nickel-based superalloy materials. Besides, it could also be used to support the results of the hardness and density tests carried out.

The results of microstructure testing on nickel-based superalloy material samples are shown in Figure 6. to Figure 8.

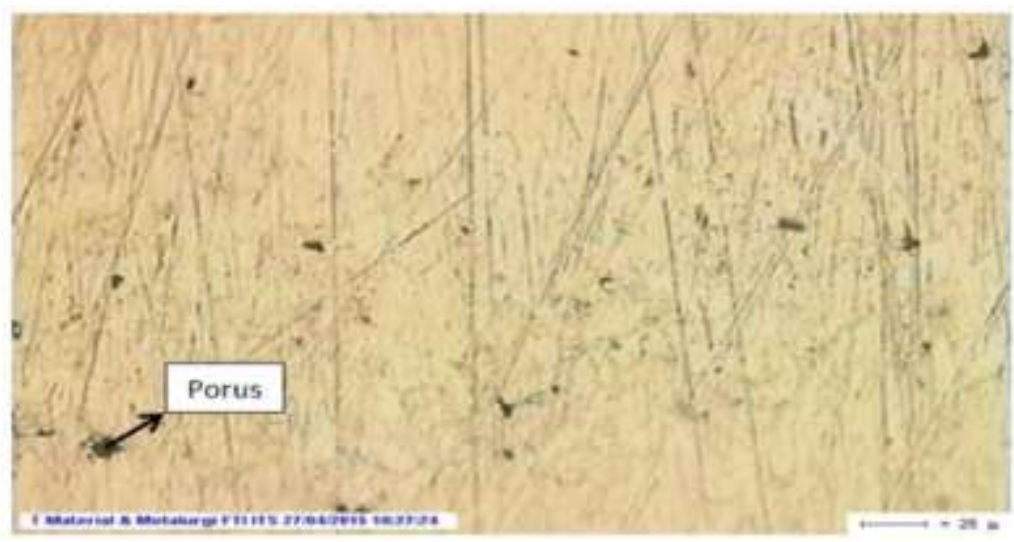

FIGURE 6. Superalloy material microstructure with 53 wt.- $\%$ Ni content. 


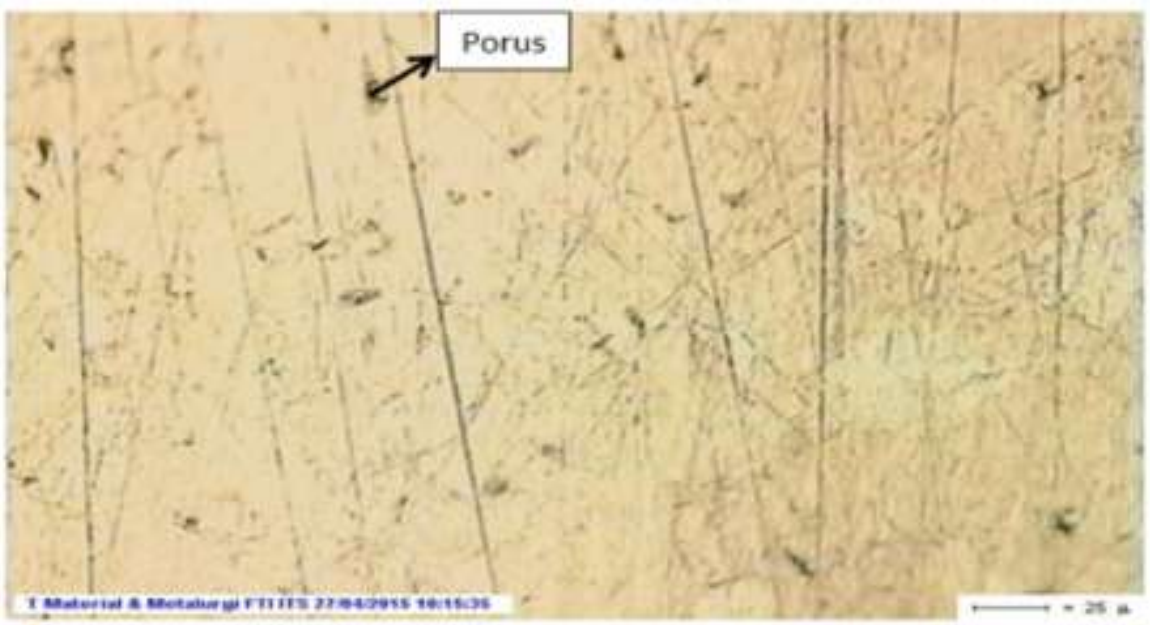

FIGURE 7. Superalloy material microstructure with $56 \mathrm{wt} .-\%$ Ni content.

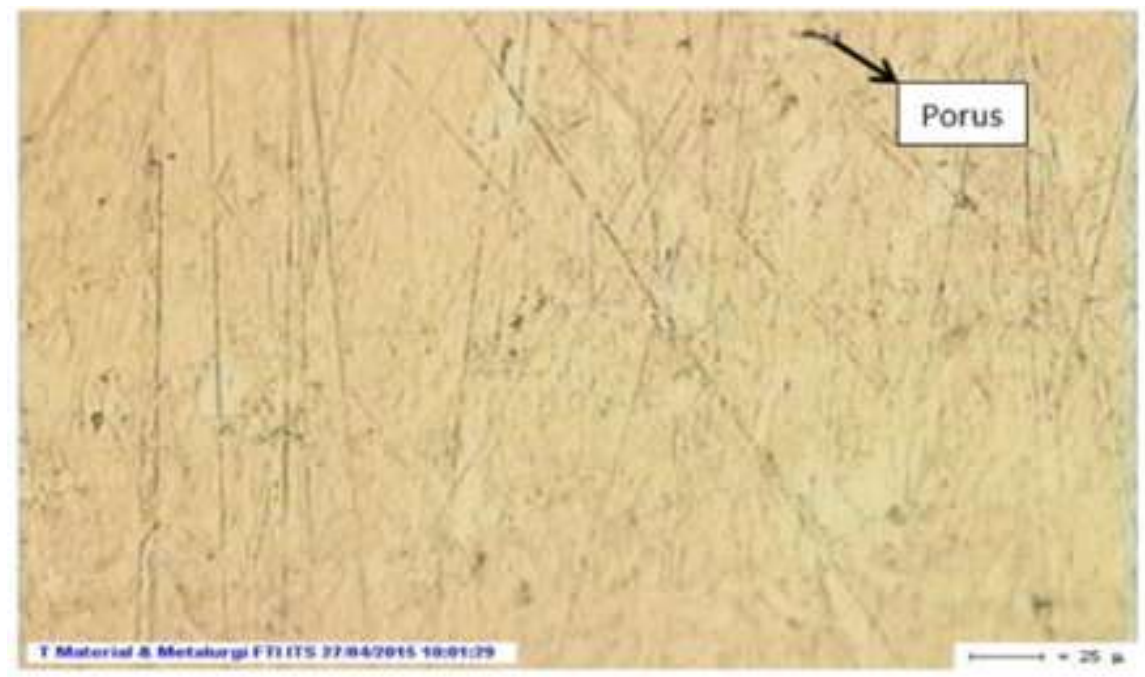

FIGURE 8. Superalloy material microstructure with 59 wt.-\% Ni content.

Based on the results of the microstructure shown in Figure 6, Figure 7, and Figure 8. It appears that the microstructure in Figure 8 forms a finer microstructure where the morphological structure of the sample is smoother and denser, and there are fewer pores than the morphological structure in Figure 6 and Figure 7. Results This also affects the density and hardness of the sample, where the morphological structure of the sample is more acceptable and denser, and the number of pores is smaller, making the density value and hardness value of the sample larger.

\section{CONCLUSION}

Nickel concentration affects the physical and mechanical properties of aircraft turbine blades. The greater the nickel content added, the greater the density and hardness of the turbine blade sample.

Based on the tests carried out, the best value was obtained, namely the nickel content of $59 \mathrm{wt} \%$, where the highest density value was $4.826 \mathrm{~g} / \mathrm{cm} 3$, and the highest hardness value was $728.0 \mathrm{VHN}$. This result is also supported by the results of the microstructure test, where the morphological structure of the sample is smoother and denser, and there are few pores. Based on the results of the XRD test, it is also shown that the sample has formed a Superalloy phase.

\section{REFERENCES}

1. Benini, Gianluigi Alberto and Ernesto. "Performance of a Turboshaft Engine for Helicopter Applications Operating at Variable Shaft Speed." Gtindia2012-9505, 2012: 1.

2. "Airplane Turbofan Engine Operation and Malfunctions Basic Familiarization for Flight Crews." 5. 2014. 
3. Andrei, Cristian. Helicopter Propulsion System. Bucharest: Cristian Andrei, 2012. Applied Thermodynamics Turbojet Engine. 2014.

4. Thomas. "Materials development in aero gas turbines." Bradford: R.J. Smith, G.J. Lewis, and D.H. Yates, 2000.

5. THE TURBOFAN ENGINE. 4 17, 2012.

6. "China Aeronautical Materials Handbook Edit Committee (Ed)." In China Aeronautical Materials Handbook, vol 2, 2nd ed, 399-418. Beijing: China Standard Press, 2002.

7. Bowman, Randy. TMS Meeting Page. http://www.tms.org/meetings/specialty/superalloys2000/superalloyshistory.html. 2000. (accessed Maret 15, 2015).

8. Utomo, Ghanie Ripandi. $\quad$ NIKEL. February $\quad 9, \quad 2011$. http://bilangapax.blogspot.sg/2011/02/nikel-dan-paduannya.html (accessed Juli 20, 2014).

9. Prasetyo, Yudi. yudi prasetyo53. Juni 30, 2012. https://yudiprasetyo53.wordpress.com/2012/06/30/pemilihan-material-tahanpanas/ (accessed Maret 15, 2015).

10. R.J. Smith, G.J. Lewis, and D.H. Yates. "Development and application of nickel alloys in aerospace engineering." 138. 2001.

11. Jones, Michael F. Ashby and David R. H. An Introduction to Properties, Applications, and Design, Fourth Edition. London: Elsevier Ltd, 2012.

12. Callister, W.D. Material Science and Engineering. New York: An Introduction, John Willey and Sons Inc, 1985.

13. A.G. Padalko, G.S. Yur'ev, G.I. Zubarev, V.I. Tsarev, and G.V. Talanova. "Synchrotron X-ray Diffraction Analysis of a Cast Nickel Alloy after Barothermal Action." Pleiades Publishing, Ltd, 2011: 1058-1063.

14. Saryanto, Hendi. Fathul Ilmi. September 9, 2013. http://fathul ilmi.blogspot.com/2013/09/teori-dasar-X-raydiffraction-xrd.html (accessed Agustus 15, 2014). 